\title{
How I found out I had a bipolar disorder: A reflexive-collaborative exploration of the process of identifying that one is struggling with a severe mental health problem
}

\author{
Marius Veseth, Per-Einar Binder, Marit Borg \& Larry Davidson
}

\begin{abstract}
Research indicates that it may take up to 10 years between onset of symptoms of bipolar disorder and receiving correct diagnosis and treatment. What is this period like? How do individuals experience the process of discovering that they have a bipolar disorder? In this study we utilized a hermeneutical-phenomenological approach developed within a reflexivecollaborative framework to explore these questions. In-depth interviews with 13 participants who reported both bipolar I and bipolar II diagnoses were conducted. We analyzed our data in collaboration with a group of 12 coresearchers who have experiences of mood disorders, and through reflexive dialogue with this group we validated and expanded our results. We describe three phases through which participants manoeuvred from (a) "uncertainty and confusion" through (b) "grasping the novel and unusual experiential states" to (c) "giving meaning to the lived experiences of intense ups and downs." These results are discussed in relation to theory, research and practice.
\end{abstract}

Keywords: bipolar disorders; recovery; hermeneutics; phenomenology; reflexivity; collaboration; service user involvement

Please cite this article as:

Veseth, M., Binder, P.-E., Borg, M. \& Davidson, L. (2013). How I found out I had a bipolar disorder: A reflexive-collaborative exploration of the process of identifying that one is struggling with a severe mental health problem. Qualitative Studies 4(1): 21-38.

\section{Introduction}

Bipolar disorders are heterogeneous mental illnesses with a lifetime prevalence of about $3.9 \%$ of the adult population (Kessler et al., 2005). People who struggle with these mental health problems are typically burdened with periods of severe depression, mania or hypomania, as well as mixed episodes. According to diagnostic criteria, bipolar I disorder is characterized by at least one lifetime manic or mixed episode; bipolar II disorder by at least one lifetime hypomanic episode along with at least one episode of major depression; and cyclothymia by two or more years of alterations between hypomanic and depressive symptoms that do not meet criteria for hypomania or a major depressive episode (American Psychiatric Association, 2000). The disorders are accordingly often described as a continuum of severity (Cassano et al., 1999). Bipolar disorders have frequent co-morbidity and hold the highest suicide rates of all mental health conditions (Proudfoot, Doran, Manicavasagar \& Parker, 2011). As such, the disorders are a considerable source of distress and suffering to persons struggling with it.

Studies indicate that it may take up to 10 years from onset of bipolar symptoms to receipt of a correct diagnosis (Hirschfeld, Lewis \& Vornik, 2003; Suppes et al., 2001). The delays between emergence of symptoms, seeking professional help, and acquiring a diagnosis and treatment, may be a significant barrier to recovery, as well as contributing to the torment of people affected (Skjelstad, Malt \& Holte, 2010; Woods, 2000). In the present investigation, we aimed to explore how the process of identifying a bipolar disorder is experienced from the first person perspective. The article extends findings presented in a previous paper in which we examined what persons suffering from a bipolar disorder do to promote their own processes of recovery. 
We found that their efforts toward improvement and growth could be summarized and described in the following themes: (a) handling ambivalence about letting go of manic states; (b) finding something to hang on to when the world is spinning around; (c) becoming aware of signals from self and others; and (d) finding ways of caring for oneself (Veseth, Binder, Borg \& Davidson, 2012).

Bipolar disorders have been described and explained primarily within a biomedical framework for the last few decades (Miklowitz, 2008; Scott, 2006). Little research has been conducted outside of this perspective during this period, and, as such, there is a need for developing new perspectives and ideas. Because of the hypothesis-generating potentials of qualitative methods, these approaches may be particularly important and useful in this context. We draw on indepth interviews conducted with 13 participants who reported both bipolar I and bipolar II disorders, and offer findings from sections of these data that focus on what it is like finding out that one is suffering from a bipolar disorder. The study was designed and conducted with a group of 12 coresearchers who all have firsthand experiences of mood disorders. The background for collaborating with these service users was to enhance the quality of the research project (Faulkner \& Thomas, 2002; Trivedi \& Wykes, 2002). Most importantly, we aimed to strengthen the ecological validity of the study by ensuring that the research questions and themes were relevant and meaningful to persons who have lived experiences of mood disorders, as well as to have our views and perspectives confronted and challenged throughout the study in an ongoing dialogue with this group of coresearchers. As such, we utilize the knowledge of two distinct groups of service users in the present investigation: the participants who shared their experiences in qualitative interviews and the coresearchers who engaged in developing and implementing the study (see also Veseth, Binder, Borg \& Davidson, 2012).

The aim of the present study was to explore first person perspectives on identifying a bipolar disorder: How do individuals experience the process of discovering that they are struggling with a bipolar disorder? What does it mean for the person to find out that their symptoms and distress are in line with descriptions commonly seen as a severe mental illness?

\section{Method}

We utilized a hermeneutical-phenomenological approach developed within a reflexivecollaborative framework to explore our research questions. This approach holds a phenomenological aim as we seek to generate knowledge about the lived experiences in finding out that one has a bipolar disorder. It is directed toward describing and exploring everyday experiences on a concrete and jargon-free level (Binder, Holgersen \& Nielsen, 2010; Kvale \& Brinkmann, 2008; van Manen, 1990). We can, however, only progress toward this aim through a hermeneutical process of interpretation in which we as researchers actively negotiate the meaning of the lived experiences - initially through engaging with the participants in the interview situation and later through a dialogue with the transcribed text (Gadamer, 1989; Heidegger, 1962). From a hermeneutical-phenomenological perspective, meaning is therein conceptualized as co-created by researchers and participants, and as such, the researchers' experiences and subjectivities are acknowledged as an unavoidable part of every study (Alvesson \& Sköldberg, 2000; Finlay, 2002; 2003; Malterud, 2001a; 2001b). The researchers' preconceptions and intentions are, however, not only sources of errors in this approach - they are also seen as providing the researchers' means to understand the participants' lived experiences (Heidegger, 1962). 
In order to enhance the trustworthiness of our study, we have aimed to make our preconceptions and intentions explicit in the present article. This is in line with a reflexive framework (Alvesson \& Sköldberg, 2000; Finlay, 2002; 2003), which has been the guiding methodological principle in carrying out the research project. When the researchers' preunderstandings are seen as giving direction to the way in which studies are planned, performed, and presented, exploring and reflecting upon these preconceptions are of importance to the quality of the research. In the present study, collaboration with our coresearchers provided us with an important tool for considering such researcher effects in detail. The different positions that we as researchers and the service users as coresearchers represent, contributed to an increased focus on this reflexive attitude. Through dialogue with our coresearchers we also became increasingly attentive to our own participation in the research project. As such, this collaboration held potential for creating a metaperspective, which again is an important strategy for continuously articulating questions to the subject matter (Malterud, 2001b).

\section{Researchers and coresearchers}

The researchers have experience with therapy in the field of mental health care and qualitative research on topics within this area. The first, second and last authors as clinical psychologists and the third author as an occupational therapist; the first author as a research fellow in clinical psychology, the second and last authors as professors in clinical psychology, and the third author as a professor in mental health care. The group of 12 coresearchers was selected from the largest service user organization in the field of mental health care in Norway and from the local health trust in the western part of the country. They all have firsthand knowledge of mood disorders and processes of recovery. Many of them have experience as service user representatives in the mental health system and most were active within service user organizations.

\section{Participants}

Thirteen informants, seven women and six men, participated in the study. Their age ranged from 27 to 65 years, with a mean age of 47 years. All were ethnic Norwegians residing in the western parts of the country. The participants reported both bipolar I and bipolar II diagnosis; and many described co-morbid clinical problems such as anxiety, post-traumatic stress disorder, psychosis and attention-deficit/hyperactivity disorder. The participants recounted that they had struggled with symptoms of bipolar disorders over the past 2 to 30 years, with a mean period of 18 years. Exclusion criteria for participation were alcohol or substance abuse as a primary diagnosis and inpatient and/or electro convulsive treatment within the past six months, so that none of the participants were in a severe episode of illness at the time of interview.

\section{Data collection}

Ten participants were recruited through their local outpatient clinic and three through advertising in the largest local newspaper in the western parts of Norway. All participants selfidentified as having experiences of recovery from bipolar disorders and contacted the first author by telephone or e-mail after reading the newspaper ad or receiving initial information about the study from their therapists. Individual in-depth interviews were chosen in order to facilitate an open exploration of participants' lived experiences. The first author conducted the interviews which ranged from 45 to 110 minutes, with most lasting about 80 minutes. They were audio-taped and transcribed verbatim. 
Data analysis

In line with our hermeneutical-phenomenological approach, we aimed at generating knowledge about the lived experiences in finding out that one is struggling with a bipolar disorder, and to attain a reflexive position where we, through collaboration with our service user coresearchers, aimed at being aware of our own participation in the research process. Our analysis was technically supported by NVivo 8 (QSR International, 2008), and proceeded through the following steps inspired by Alvesson and Sköldberg (2000), Finlay (2002; 2003), Kvale and Brinkmann (2008), Malterud (1993), and van Manen (1990):

1. The first author noted his initial impressions after conducting and transcribing each individual interview, and discussed important topics that arouse with the second author.

2. The first, second, and third author thereafter read all the transcriptions to obtain a basic sense of them (Malterud, 1993).

3. Exploring those parts of the interview that were of relevance to the research questions, the first author identified units of meaning that represented different aspects of the participants' experiences and discussed them with the second author (Kvale \& Brinkmann, 2008).

4. The first author then developed codes or keywords for those units of meaning.

5. The meaning within each of the coded groups of text was thereafter interpreted and condensed into everyday language by the first author (Kvale \& Brinkmann, 2008).

6. The content of each code was summarized into overall descriptions of themes and meaning patterns that reflected the first author's understanding of what emerged as the most important aspects of the participants' experiences (van Manen, 1990).

7. For validation and reflexive purposes (Alvesson \& Sköldberg, 2000; Finlay, 2002; 2003), the first author then presented these themes along with de-identified extracts of the transcribed text to the coresearchers in a two-day collaborative meeting in which the second and third authors also participated.

8. The second author led a process in which the group of coresearchers critically audited the themes and negotiated a common orientation to the phenomenon of study (van Manen, 1990). This process was recorded by the first author in notes in which he aimed to pay attention to both the homogeneity and heterogeneity of the group's interpretations.

9. The first author thereafter reorganized the themes and discussed the research process and resulting meaning patterns with the last author.

10. Finally, the themes were formulated and agreed upon by all authors, and presented for a concluding validation at another collaborative meeting with the coresearchers.

Ethics

The study was approved by the Regional Committee for Medical and Health Research Ethics Western Region and the Norwegian Social Sciences Data Services. Informed consent was a requirement for participation. Before the service user coresearchers were presented extracts of the transcript material, they signed a declaration of confidentiality and all identifiers were removed. The participants were informed of the coresearchers roles and participation in the project.

\section{Findings}

In the individual interviews, the participants described how they first experienced various symptoms and problems that they later identified as a bipolar disorder. This process of learning 
and recognizing their distress was experienced as a challenging and enduring enterprise. For some it was a sudden shattering of their worlds, for others a lurking feeling that something was wrong. All of them, however, described this process as hard and demanding, as it required that they began to give meaning to the intense experiences of not knowing what was happening to them. In their efforts, the participants gradually started to acknowledge that their emotional and psychological distress was in line with descriptions commonly seen as a severe mental disorder. This was a strenuous and painful task for many, but it also created an important momentum to discover what they actually could do to overcome their symptoms and distress. In our presentation, we have organized the participants' descriptions of how they found out they were struggling with their mental health into three phases through which they manoeuvre from (a) "uncertainty and confusion" through (b) "grasping the novel and unusual experiential states" to (c) "giving meaning to the lived experiences of intense ups and downs."

\section{"I didn't recognize myself anymore" - Uncertainty and confusion}

An initial state of not knowing what was happening to them was a common description among participants in the present study. All of them highlighted a phase of uncertainty and confusion in their lived experiences of finding out they were battling a mental health problem. For some of the participants, this phase was characterized by a growing feeling that something was wrong. They had for some time noticed experiences that were difficult to comprehend and relate to. Others described the onset and unveiling of their symptoms as an acute breakdown. Suddenly they were hammered by intense experiences they could not understand. In both cases, participants experienced various symptoms and problems as both extremes of moods high and low - started to affect their lives in new and different ways. These evolving bodily, emotional, and psychological phenomena puzzled and confused them. A description of how a blurring and novel feeling of sadness developed as a boyfriend left one of the participants can illustrate this:

When this man left me, I gradually became more depressed. And that was kind of a new experience to me. I had been sad earlier, but this time my thinking started to become... I didn't manage to do things, organize things the way I had been able to earlier. And it was very chaotic. Very chaotic. It was an unfamiliar feeling to me, but I didn't think of it like a depression, I wasn't able to see it from the outside.

In another interview, a young woman reflected on how she experienced the unveiling of her first episode of elevated mood. As in the description above, this participant highlighted the sense that something was going on, and at the same time she felt that she was not able to understand what it was. For her, the "something" was experienced as originating in her body. It was a kind of tingling or distress that she was struggling to figure out and comprehend. In the following account she described how she suddenly found herself shaky and distressed at a holiday trip with a friend:

When I had been there for about three days, I felt there was something happening to my body, and my friend felt like she didn't know me at all. She was wondering if I had been doing drugs or something, and was very upset with me. Actually, I had only been drinking water and eating some fruit, I hadn't been liquoring up at all, so I didn't understand what was going on. That's when we found out we had to go look for a hotel so that we could get some peace and quiet as an alternative to the motel we were living in. ... And as we were out looking, I felt a tingling in my body. I thought I was having some kind of sun stroke or something. I was really off. 
For many of our participants, not being able to make sense of these experiences was challenging. A growing awareness that something is happening to oneself and at the same time not getting hold of what it is, can be scary - particularly so when the experiences are as colorful and intense as they can be in periods of elevated mood. A female participant described her first experiences of these vivid and altered psychological states as a frightening feeling of her mind being like a high speed rail that was running continuously. However, she did not realize what was going on as she just thought she was "all stressed out." This uncertainty and confusion created an increasing need to respond to the psychological and emotional state that developed. In the interview she described how she eventually stepped in and started the process of addressing what was going on in her life:

Then I thought this isn't working out, I had only a few hours of sleep night after night. I got up in the morning, started at about five a.m. and was full of energy. I had only slept an hour or two, three, four hours. That was when I thought - this isn't normal, this isn't who I am. I have been all stressed out before, but I have never been like this.

The participants' need for awareness and understanding was met by engaging others who could help them in this process. As such, the uncertainty and distress seemed to drive many to make connections that could enable them to understand more of what was going on. A male participant, for example, described that even though he had no prior experiences with psychiatric treatment or services, he intuitively felt the need for mental health care when he experienced a new and different kind of pressure:

Interviewer (I): Can you tell me about how you first found out you had a bipolar disorder?

Participant $(\mathrm{P})$ : Then we'll have to go back several years. . . I was working full time, and got a lot of work from my employer. That is, it was a lot of pressure [at the time], and suddenly, in only a few weeks, it all built up. And I had never heard about psychiatry or anything, but I understood that something was wrong and got to see my company's on-site doctor. Instinctively I understood that I was in need of psychiatric assistance, I didn't know what it was, but I knew I needed psychiatric help.

Participants' first step toward awareness and understanding was in this way an active one. By deciding to communicate their uncertainty and confusion to others, the participants initiated a movement toward the next phase in finding out what their unusual experiences were about. The interview with the young woman, who was on vacation when a novel and intense state of elevated mood developed, can help to shed light on this. She described how she started to talk to her friend about her experiences. Together they then agreed upon making contact with the local health authorities:

That's when we talked about that something was not right. I was in despair, I didn't recognize myself anymore. I was very stressed and very shaky. . . And that's when we found a small local hospital where we got help immediately.

"Now you're either manic, mum, or you've won the lottery" - Grasping the novel and unusual experiential states

We have interpreted our participants' commencing efforts to grasp and understand their experiences as the second phase in the process of finding out they were battling a mental health 
problem. In order to move beyond their feelings of uncertainty and confusion, the participants approached their experiences through discussing them with others. Some of them initially talked to their family or friends, but eventually all made contact with health care professionals. For some, these relationships were established quite quickly, but most had suffered symptoms and pain for many years before they got in touch with the health care system. As a first step toward grasping their distress and relieving their despair, the participants in this phase disclosed their experiences and feelings. One of them described how she explicitly had thought about the possibility that her symptoms and distress could be coined a bipolar disorder. However, despite her suggestions and proposals, she still did not receive health care that could meet her needs:

I've had problems with mental fluctuations and depressions since I was young, and I've had many turns with the health care system, to medical doctors, referrals to clinical psychologists. That is, I approached many people and said that there is something I need help with. . . . I don't think I ever got a thorough screening, but what I knew was that my grandfather was manic-depressive and that some of his brothers and sisters were ill too. And that there was something... I knew my mother had struggled with depressions and that there was something with my own experiences of... I didn't think in terms of mood, I didn't use that vocabulary at the time. But there still was something that made me think - is there something to it? At one point I asked a psychologist I was in treatment with openly. . . But I didn't get any answers. It was on the one hand like this, and, on the other, like that.

Most of our participants, however, did not have as concrete ideas or straightforward approaches as this woman. As such, many of them described spending years battling the system as well as their symptoms in this process. Their initial feelings of uncertainty and confusion made them anxious and insecure, and for many this anxiety was enlarged and prolonged as they experienced that others were also unable to understand what was going on. This was particularly pertinent in relationships with professional health care workers - the kind of others the participants expected and counted on to be capable of offering them some help in relation to their distress. Many of the participants in this study highlighted negative experiences related to this. One of them described, for example, being given medication for gastroenteritis while presenting a major depression, another how a nurse at an intensive care unit tried to talk her out of transferring to a mental hospital because she could be in danger of disappointing her family and friends. A third participant elaborated this point further. She had initially thought her mood fluctuations were the effect of premenstrual syndrome or possibly the aftermath of an infertility treatment. Gradually she then started to develop a feeling that there had to be something more to it:

P: I summoned my courage, I realized that it was mental, and went to a medical doctor who stood with her back onto me, arranging her hair, and... I spilled my guts, I divulged my soul and secrets, for the first time I talked about it. And when I was all set, at first I was there to do some samples, and when I was all set I received a letter that I might be anemic. At that moment I fell apart. Because the prize of making my problems known was very high at that time, and she didn't see the issue at all.

I: What did you say to her?

P: I told her that I had the most gorgeous child, I had a sweet and supporting husband, I had a nice house and all. But nevertheless, I was in the dumps. I cried from the time I left work on Friday until Sunday afternoon, I was desperate and everything was off. 
And when I went to work I just stood in the resting facilities shedding my tears, hoping that no one could see me, because then I would have broken down. And then she says that I might be a little anemic.

One of the male participants had until recently very similar experiences with the health care system. He had received little or no help from his doctors besides symptomatic medication, and described how he over a long period of years had moved from one episode of illness to another. Eventually he was not able to put up with his demanding position as a leader and had to take sick leave. At the time he had massive digestive problems and struggled to catch on to how these complaints were related to his mental health. This time, however, he met a general practitioner who was able to help him start to grasp these experiences. In the interview, he described how he felt the relationship between his stomach-related problems and his mental health issues got uncovered by his doctor:

How I first found out I had a bipolar disorder? Let me put it in a different way - how I got unmasked by my medical doctor who then intervened and helped me. And in that process, I was diagnosed with bipolar disorder as well as generalized anxiety, social phobia and post-traumatic stress disorder. . . . But I had my first downers when I was about 18 or 19 years old, maybe even earlier. What happened then was that I saw our family practitioner who gave me a box of pills, antidepressants I think, which I ate and perhaps got a little better. Thereafter I had new setbacks and got new boxes of pills. But I never knew that I had a disorder in any way, it was just that I had a hard time and needed help to get back on my feet again. . . . And when my doctor looked at me and said: Are you depressed? - at that point she unmasked me, she brought light to what the problem was.

To approach and grasp such confusing periods of bodily symptoms and extended sadness was, however, not sufficient to find the appropriate treatment and care for the participants in the present study. For some of them, identifying these episodes of depression only led to a temporary feeling of being understood, as treatment with antidepressants was of little help for their problems and distressing life situation. Instead, this seemed to worsen the course of their symptoms, as it triggered for many participants an intense period of elevated mood. They were once more left feeling uncertain, confused and not being listened to as their symptoms and distress escalated and intensified. The following account describes how a female participant experienced the onset of a manic episode. She was at the time trying to communicate her growing feelings of anxiety and despair as psychotic symptoms emerged. Paradoxically, it was ultimately her son who identified her unbearable complaints as a manic episode:

P: I started on [antidepressants] and was supposed to talk to my general practitioner again. ... I made contact with my doctor, I don't remember how many days I used the medication, but I responded extremely from day one. I made contact with my doctor and said that I'm not sure that I have nerve to use the medication any more because I'm going crazy, I'm afraid of becoming psychotic. . . Because there is something strange going on that has never happened to me before. But no, I shouldn't stop taking my medication, I shouldn't stop. . . . I observed by myself that there was a change and that... And then, then I became very ill.

I: What was it that changed?

P: Well, I became psychotic. Everything was... I went to my doctor and said that everything was fantastic, all my problems were going away.... And at the same time as 
I felt that all my problems were going away, I had a panic attack. When I tried to communicate to her how I was doing, I used two images, because there was something going on that I had never experienced before. The first was that I was running on ice and I had to run faster and faster to keep me from falling. The second was that I felt like a runaway horse. At that time I was psychotic. And before I got hospitalized, I sat in my kitchen, and my son said, he suspected it, that now you're either manic, mum, or you've won the lottery.

Communicating these confusing states associated with the extremes of moods in mania and depression can be hard. The experiences that the participants had not yet developed the words to describe, can for many of them have triggered a need to simplify and concretize their complex experiential world. This, in turn, may have created challenges in their communication with the health care professionals. As such, the participants were clearly in need of an especially attentive and caring health professional at this point in the process of discovering their mental health problems.

"I've been wondering if that's enough, am I thereby manic-depressive?" - Giving meaning to the lived experiences of intense ups and downs

As our participants moved from their initial feelings of uncertainty and confusion, through a phase of seeking help from others in starting to grasp their novel and unusual experiences, they eventually arrived at a place where they began developing ways of giving meaning to these extreme bodily, emotional and psychological states. One example of reflections that characterize this phase can be drawn from an interview with a female participant who retrospectively tried to relate her lived experiences of intense ups and downs to the diagnostic terminology of a bipolar disorder:

I: What's it like to think back on this period now?

P: No, it's... It's emotional, of course, because it's not something I reflect much upon today... But I've thought about it like... Okay, the first thing that happened, that was a depression. But then what... And then a manic period followed, that's true. But I've been wondering if that's enough, am I thereby manic-depressive? Because it's kind of... At least it felt very natural. After being in a state of void and meaninglessness, when I once again felt meaning and worth... It seems to me more of a normal reaction.

I: For you it felt like... You think of it as natural.

P: Yes. And also the thing that happened afterwards, the [childbirth] ... They say it is normal to have special reactions ... because of the hormonal changes.

People make sense of their experiences in different ways. As such, the phase of giving meaning to the states in both extremes of mood was built up by a multitude of views and reactions. Some of the participants weighted their responses to the diagnosis in this process. It could be experienced as carrying stigma and sometimes like a prophecy of doom. Others, again, focused on how their growing understanding of what was going on could be a comfort and relief. For many of them, recognition and acceptance enabled them to work on their problems and distress. In the interviews, most of our participants described nuances of both these polarities. We have termed the subthemes "challenges in defining one's symptoms" and "recognition as a step toward recovery."

Challenges in defining one's symptoms. Being diagnosed with a mental illness can be a demanding and challenging exercise. Some of the participants in our interviews put weight on this aspect in 
the process of giving meaning to their experiences. For them, understanding and labelling their symptoms and distress as consequences of a bipolar disorder was not necessarily helpful. One participant elaborates on this point in the following words:

P: The only thing is that I don't feel I have gained something when trying to understand myself. Being given that diagnosis with... That it... It is, you know, categorized as serious, isn't it?

I: Well...

P: Serious or severe or something like that. And that... Being given that label without anyone trying to make me more comfortable with it or help me increase my understanding of it... What kind of consequences this may have... It's just that I'm left with too many questions in relation to this.

Other participants went even further with regards to this. For them, the diagnosis became another painful problem they had to deal with. A male participant described it initially as doubling his burden, as he already had an anxiety condition he had spent years battling, and a female participant highlighted how difficult it was to integrate and relate the diagnosis to her sense of self:

That's part of my suffering right now, the pain related to the diagnosis. I know that this is different from person to person, but to me it wasn't a relief being given the diagnosis. I thought it was totally awful because it carries so many conceptions in me and in the society too. ... Totally awful that my children must have a mother with this diagnosis, that's the worst part of it. But I acknowledge that there has been too much drama in my life. I do see that there are things that support the diagnosis. ... It's not that I'm of the opinion that the diagnosis is wrong, but it's been extremely difficult for me to relate to. They introduced it as, I'm not sure whether they called it bipolar or if they used the term manic-depressive. It's possible that they called it bipolar, but anyway, manicdepressive, severe mental disturbance. No, that was... To integrate that as part of self... That is - I am severely mentally disturbed? Dear God, I am... And then I thought - no, that means that everything is over, I have nothing to look forward to.

At the same time, this woman acknowledged that her diagnosis was important as something she could relate her experiences to, as well as to provide information on how she could navigate in her daily life to keep well. But still, identifying with the diagnosis and integrating it as part of her sense of self was a difficult and utterly distressing task. Another female participant responded similarly when the interviewer posed a question about what the process of assessment and being diagnosed was like. She found acceptance particularly challenging as a family member she was displeased and sickened with had had the same diagnosis of bipolar disorder:

I didn't like it. I didn't like it at all. And that was probably because of the knowledge I have about it through my brother. I don't look at myself like that at all. But I do appreciate that professionals have assessed me, and in my experience no one wants this, most people deny it, and I guess I think it's better to accept that I have this and work from that position rather than battling the diagnosis.

Recognition as a step toward recovery. An important part of giving meaning to the experiences of mania and depression was to find ways of relating to the multifaceted aspects of these 
phenomena. Many of the participants had experienced loneliness and alienation in the process of finding out that they were battling a bipolar disorder, and these difficult feeling states were enlarged and prolonged as they recognized that others were unable to help them understand what they were going through. With regards to this, discovering that they had a bipolar disorder could be a relief, as the participants finally experienced that they were not alone and detached anymore. One of the participants highlighted this process of identification as she described the value of a group-based intervention she attended at her local outpatient clinic:

Even though they didn't have the same diagnosis as me, they had other problems and other diagnoses. And... to put a face on mental illnesses and meet other people who were like me. Normal... All kinds of ages and life situations and... A lot of young ladies... To be able to talk together and be together, that was very important. Yes, it was. Previously I felt like I was the only one being ill, and then I arrive and meet so many others who live well organized lives, just like everybody else. That gave me courage to keep fighting.

Figuring out and being able to give meaning to their experiences was also comforting and reassuring to many of the participants. They contrasted their present symptoms and distress with the uncertainty and confusion that coloured their first experiences of the emotional and psychological shifts of intense ups and downs. Said one participant:

Had I, when I first became ill, known that I was ill, I would probably not have tried to commit suicide. Do you get it? I didn't know that I was ill, I was just not worth anything. That's what's helped me later - that when I'm ill, I know I'm ill, that there is help out there.

As such, for many of the participants, discovering their symptoms and distress created an important momentum in their recovery. One of the participants underscored this period as a turning point in her processes of healing and growth:

I: Thinking back on this process, when was it that you first felt you were improving or that you were in recovery?

P: I think it was when I received the diagnosis. I think it was then, when I was given proper medication. I think that's when I felt that I was able to see the light in the tunnel and start to work my way back to life....

I: So it was in the beginning, when you received the diagnosis and started on the medication. That was an important period.

P: That was a hard period. To kind of accept that one is ill. But it was also... It sort of lit a fire at that point. Now I have received a diagnosis, now I have got my medication, and now I can start.

\section{Discussion}

What do our findings tell us about the experience of finding out that one's problems and symptoms can be understood as a bipolar disorder? How is this exercise of giving meaning to one's distress related to the processes of recovery? And what are the implications of our findings for practice? In this study, we have presented the process of discovering a bipolar disorder from a first person perspective. We have identified three phases as our participants move from (a) "uncertainty and confusion" through (b) "grasping the novel and unusual experiential states" to (c) "giving meaning to the lived experiences of intense ups and downs." 
These phases are seen as themes that describe an epistemological movement through which participants start to create a new understanding of who they are and what they can become. We interpret this progression towards recognition as both a challenge as well as a drive in the participants' processes of recovery.

From feeling lost to the ambiguity and diversity of finding out

What is happening to me? Why does everything seem so grey and dull? What is going on? Why are my thoughts and feelings racing away? These are questions the participants asked themselves in the initial phase of "uncertainty and confusion." A sense of being lost arouse for many as their lives and experiences were suddenly unknown and incomprehensible. In order to approach and understand this phenomenon, we may turn to Heidegger's (1962) notion of Unheimlichkeit in which he describes and explores experiences of uncanniness and unhomelikeness. This concept has been seen as important to understand the phenomenology of illness (Svenaeus, 2000a; 2000b) and as notable in the process leading up to an existential breakdown in exhaustion disorder (Jingrot \& Rosberg, 2008). Finlay and Molano-Fisher (2008) have moreover demonstrated how it also can be of significance in comprehending other phenomena, as they argue that the concept is helpful in approaching the existential anxiety that can follow the transformed lifeworld after a cochlear implant.

According to Heidegger (1962), we have a fundamental familiarity with our lifeworld, a homelikeness, that co-exists with uncanniness and unhomelikeness, feelings of being alienated or not at home: "This is my world, but it is also at the same time not mine, I do not fully know it or control it" (Svenaeus, 2000b, p. 215). Heidegger (1962) argues that this basic Unheimlichkeit may lead to existential anxiety, moments in which the world looses its meaning. In his presentation and interpretation of Heidegger's philosophy, Svenaeus (2000a; 2000b) makes use of this concept in understanding health and illness. Illness is here seen as a rupture in the familiarity, balance, and rhythm that characterize good health. Feelings of being unhomelike and out of tune will gradually emerge as illness sets in: "Where there was earlier a homelike attunement, there is now the growing despair of uncanniness" (Svenaeus, 2000a, p. 12).

In our participants' process of finding out they were battling a bipolar disorder, many described how they were not able to recognize themselves anymore. They highlighted frightening sensations of something happening to their bodies and unfamiliar feeling states that suddenly seemed to arise. As such, our participants described a growing anxiety and alienation - what may be described as an evolving state of Unheimlichkeit. These experiences of being lost, strange or out of control were in our material further amplified as people around the participants were also unable to understand and give meaning to their experiential world. Why do not my family and friends recognize me either? And what does it mean than not even my doctor or therapist seems to know what is going on?

The participants' lived experiences of not being able to understand and control what was going on in their daily lives were in some ways validated and confirmed through their initial meetings with others. Many described how no one seemed to be able to help them make sense of their symptoms and distress. As such, the described phase of "grasping the novel and unusual experiential states" that emerged in the participants' lives prolonged and enhanced their feelings of uncanniness and unhomelikeness, their experiences of not knowing and not controlling their own lives. According to Lam and Wong (2006), it is often observed in clinical work with persons with bipolar disorders that depression can spiral down and mania can fuel itself. As such, this kind of existential anxiety can be an important aspect in the first person 
perspective of battling such mental health problems. A particularly crucial challenge when facing bipolar disorder may therefore be to find ways of taking charge in one's own life. But how can individuals wrestling a bipolar disorder go about resuming control and promoting their personal recovery? How can the person regain his or her feeling of homelikeness?

In the present study, we find that two different roads characterize participants' experiences in the phase of "giving meaning to the lived experiences of intense ups and downs." While the participants were similar in their descriptions of the first two phases, their experiences of developing ways of understanding their symptoms and distress were more varied and divergent. As such, we may say that a heterogeneity characterized their experiences of this phase. Many of the participants felt comfort and relief as they eventually were able to recognize and understand that they were battling a bipolar disorder. Others emphasized that they struggled to find themselves at home in the diagnosis and descriptions of a severe mental disorder. Thus, knowledge and recognition seemed to be important to, as well as a challenge in, the participants commencing processes of recovery. The security of knowing what is going on in one's life can in many ways be seen as principal to initiating one's personal recovery. Several studies have shown that accepting that one is struggling, being able to manage one's symptoms and resuming control in one's daily life are important to processes of improvement and growth (Davidson, 2003). Acceptance, management and control presupposes, however, that one is able to recognize what is happening in one's life. For some of the participants in our study, recognition also indicated that they were not alone as they found an implicit 'we' in the diagnosis. To them, the phase of giving meaning to symptoms and distress may therefore have been an important answer to the loneliness, alienation, and anxiety they had experienced.

At the same time as the participants weighed these favourable sides of recognition and understanding, they had clear experiences of not wanting the label that the diagnosis constituted. Deegan (1993) describes similarly how she experienced that others suddenly got blind to the person she was and tended to see her only as an illness when she was diagnosed with a major mental illness. This was particularly challenging with regards to initiating her processes of recovery:

Once a person comes to believe that he or she is an illness, there is no one left to take a stand toward the illness. Once you and the illness becomes one, then there is no one left inside of you to take on the work of recovering, of healing, of rebuilding the life that you want to live (Deegan, 1993, p. 9).

From this perspective, recovery is not necessarily about finding a homelike feeling in one's symptoms and distress, but may as well be about building a new house that one can call home. Following this line of thinking, Davidson et al. (2007) have defined recovery as "a process of restoring a meaningful sense of belonging to one's community and positive sense of identity apart from one's condition while rebuilding a life despite or within the limitations imposed by that condition" (p. 25).

\section{Methodological limitations and strengths}

In order to ensure the integrity and increase the validity in qualitative research projects, monitoring and evaluating one's own presence in carrying out a study is of importance to the quality of the research (Finlay, 2002). In many ways, this is an exercise of sidestepping in which the aim is to make one's position and preconceptions explicit and transparent to both oneself as well as the audience. This may provide what Malterud (2001b) metaphorically calls "the 
knower's mirror" - a frame in which researcher and readers are offered the context of the study so as to be able to evaluate and understand the whole process of carrying it through. In the present study, we have given relatively many quotations to enable the reader to see the ways in which we have reached and understood our findings.

Collaboration with our service user coresearchers provided us with an important tool for working with a reflexive attitude throughout the research process. The approach also holds, in our opinion, the potential of both validating our results as well as expanding our understanding of them. As the coresearchers and participants were two distinct groups of persons, we were able to keep close to the phenomena of study by maintaining the context and references that firsthand knowledge may represent, and at the same time the approach made possible the necessary distance for approaching and understanding differences in such experiences. When analyzing one's own experiences, for example, this may be particularly challenging. One example of contributions from our coresearchers can be drawn from the meetings focusing on data analysis. In the initial interpretation and condensation of the first phase of "uncertainty and confusion," the first author weighted anxiety as a central aspect of the participants' experiences in the process of finding out that they were battling a bipolar disorder. In their auditing of the data, however, the coresearchers put equal weight on solitude and alienation at this point in the process. Where we as researchers saw illness in our interpretations, the service user coresearchers then saw existential themes - where we emphasised anxiety, the coresearchers also made us aware of the loneliness in this phase. Through this process, then, the coresearchers both endorsed our interpretation of the data and elaborated on our understanding of the phenomena (see also Veseth, Binder, Borg, and Davidson (2012) for an additional discussion on our experiences of collaboration in this research project, and Moltu, Stefansen, Svisdahl, and Veseth $(2012 ; 2013)$ for a study of the coresearchers experiences of doing collaborative research).

In the present study, the participants highlighted the health care system as important in their efforts to give meaning to their intense experiences - both for good and for bad. It is possible that for some persons battling a bipolar disorder, other institutions could have played an equally important role in these processes. Spirituality or faith may, for example, hold potential for contributing to the development of meaning in many people's lives. However, because most of our participants were recruited from within the health care system, we were not able to reach persons who could have described and elaborated more on these experiences. Furthermore, it is also possible that the interviewer's background as a clinical psychologist may have influenced the dialogue in direction of focusing on experiences within the health care system. If the study had been conducted by a social anthropologist or a religious leader, it may be likely that we could have found other ways of giving meaning to one's symptoms and distress that were equally important.

Another possible limitation in the present study is the relatively small and homogenous group that our participants constitute. They were all adult ethnic Norwegians who lived under the same cultural horizon. The participants had battled their symptoms and distress during the same period of time and had dealt with a more or less identical health care system. However, as we have aimed at being transparent in our methods, as well as in our presentation of our findings, the reader can independently evaluate if our findings and interpretations can be translated to his or her particular cultural context. 
Implications for practice

A key finding in our presentation is that the experience of discovering that one's symptoms and distress disclose a bipolar disorder is a diverse and multifaceted process. We believe that one important consequence of the present study is that it underscores the need for a multitude of treatments and ways of supporting individuals in their own personal recovery. This may be particularly pertinent in bipolar disorder as the diverse and multifaceted process traditionally has been met by a uniform approach to therapy in which medication has been described as the only real treatment option.

Another important finding in our study is the significance of giving meaning to the lived experiences of symptoms and distress. We are of the opinion that professional helpers should put more weight on this process when conducting treatment. Our findings indicate that it may be of importance that therapists give the person battling a bipolar disorder time and space to initiate his or her own process of creating meaning. In this way, professionals can become a complementary part of the joint creation of new understandings of the person's problems and processes of recovery, instead of being in danger of imposing their own therapeutic perspectives onto the individuals.

\section{Conclusion}

In the present study, we have explored the lived experiences of finding out that one's symptoms and distress are in line with what is commonly described as a bipolar disorder. We have interpreted this process as three phases through which the participants move from (a) "uncertainty and confusion" through (b) "grasping the novel and unusual experiential states" to (c) "giving meaning to the lived experiences of intense ups and downs." We have discussed our results in relation to theory and research, considered the process of conducting the present study, explored possible strengths and limitations, and finally outlined some implications for clinical practice.

\section{Acknowledgements}

We are indebted to the participants in the study for sharing their views and experiences. In addition, we thank our coresearchers for their valuable contributions.

\section{Funding}

The project was financed with the aid of EXTRA funds from the Norwegian Foundation for Health and Rehabilitation.

\section{References}

Alvesson, M., \& Sköldberg, K. (2000). Reflexive methodology: New vistas for qualitative research. Thousand Oaks: Sage.

American Psychiatric Association (2000). Diagnostic and statistical manual of mental disorders (4th ed., Text Revision). Washington, DC: Author.

Binder, P. E., Holgersen, H., \& Nielsen, G. H. (2010). What is a "good outcome" in psychotherapy? A qualitative exploration of former patients' point of view. Psychotherapy Research, 20, 285-294. 
Cassano, G. B., Dell'Osso, L., Frank, E., Miniati, M., Fagiolini, A., Shear, K., . . Maser, J. (1999). The bipolar spectrum: A clinical reality in search of diagnostic criteria and an assessment methodology. Journal of Affective Disorders, 54, 319-328.

Davidson, L. (2003). Living outside mental illness: Qualitative studies of recovery in schizophrenia. New York: New York University Press.

Davidson, L., Tandora, J., O'Connell, M. J., Kirk, T., Rocholz, P., \& Evans, A. C. (2007). Creating a recovery-oriented system of behavioral health care: Moving from concept to reality. Psychiatric Rehabilitation Journal, 31, 23-31.

Deegan, P. E. (1993). Recovering our sense of value after being labeled mentally ill. Journal of Psychosocial Nursing, 31, 7-11.

Faulkner, A., \& Thomas, P. (2002). User led research and evidence-based medicine. British Journal of Psychiatry, 180, 1-3.

Finlay, L. (2002). "Outing" the researcher: The provenance, process and practice of reflexivity. Qualitative Health Research, 12, 531-545.

Finlay, L. (2003). Through the looking glass: Intersubjectivity and hermeneutic reflection. In Finlay, L. \& Gough, B. (Eds.) Reflexivity: A practical guide for researchers in health and social sciences (pp. 105-119). Oxford: Blackwell Science.

Finlay, L. \& Molano-Fisher, P. (2008). 'Transforming' self and world: A phenomenological study of a changing lifeworld following a cochlear implant. Medicine, Health Care and Philosophy, 11, 255-267.

Gadamer, H.-G. (1989). Truth and method, London: Sheed \& Ward.

Heidegger, M. (1962). Being and time, Oxford: Blackwell.

Hirschfeld, R. M. A., Lewis, L., \& Vornik, L. A. (2003). Perceptions and impact of bipolar disorder: How far have we really come? Results of the national depressive and manicdepressive association 2000 survey of individuals with bipolar disorder. Journal of Clinical Psychiatry, 64, 161-174.

Jingrot, M., \& Rosberg, S. (2008). Gradual loss of homelikeness in exhaustion disorder. Qualitative Health Research, 18, 1511-1523.

Kessler, R. C., Berglund, P., Demler, O., Jin, R., Merikangas, K. R., \& Walters, E. E. (2005). Lifetime Prevalence and Age-of-Onset Distributions of DSM-IV Disorders in the National Comorbidity Survey Replication. Archives of General Psychiatry, 62, 593-602.

Kvale, S., \& Brinkmann, S. (2008). InterViews: Learning the craft of qualitative research interviewing ( $2^{\text {nd }}$ ed.). Thousand Oaks, CA: Sage. 
Lam, D., \& Wong, G. (2006). Bipolar relapse. The importance of early warning signs and coping strategies. In Jones, S. H. \& Bentall, R. P. (Eds.) The psychology of bipolar disorders. New developments and research strategies ( $p p$. 179-202). Oxford: Oxford University Press.

Malterud, K. (1993). Shared understanding of the qualitative research process: Guidelines for the medical researcher. Family Practice, 10, 201-206.

Malterud, K. (2001a). The art and science of clinical knowledge: Evidence beyond measures and numbers. The Lancet, 358, 397-400.

Malterud, K. (2001b). Qualitative research: Standards, challenges, and guidelines. The Lancet, $358,483-488$.

Miklowitz, D. J. (2008). Adjunctive psychotherapy for bipolar disorder: State of the evidence. The American Journal of Psychiatry, 165, 1408-1419.

Moltu, C., Stefansen, J., Svisdahl, M., \& Veseth, M. (2012). Negotiating the co-researcher mandate - service users' experiences of doing collaborative research on mental health. Disability and Rehabilitation, 34, 1608-1616. Published online 2012 April 10.

Moltu, C., Stefansen, J., Svisdahl, M., \& Veseth, M. (2013). How to enhance the quality of mental health research: Service users' experiences of their potential contributions through collaborative methods. American Journal of Psychiatric Rehabilitation, 16, 1-21.

Proudfoot, J., Doran, J., Manicavasagar, V., \& Parker, G. (2011). The precipitants of manic/hypomanic episodes in the context of bipolar disorder: A review. Journal of Affective Disorders, 133, 381-387. doi:10.1016/j.jad.2010.10.051

QSR International (2008). NVivo 8. Victoria, Australia: Author.

Scott, J. (2006). Psychotherapy for bipolar disorders - Efficacy and effectiveness. Journal of Psychopharmacology, 20, 46-50.

Skjelstad, D. V., Malt, U. F. \& Holte, A. (2010). Symptoms and signs of the initial prodrome of bipolar disorder: A systematic review. Journal of Affective Disorders, 126, 1-13.

Suppes, T., Leverich, G. S., Keck, P. E., Nolen, W. A., Denicoff, K. D., Altshuler, L. L., . . Post, R. M. (2001). The Stanley Foundation Bipolar Treatment Outcome Network: II. Demographics and illness characteristics of the first 261 patients. Journal of Affective Disorders, 67, 45-59.

Svenaeus, F. (2000a). Das unheimliche - Towards a phenomenology of illness. Medicine, Health Care and Philosophy, 3, 3-16.

Svenaeus, F. (2000b). The body uncanny - Further steps towards a phenomenology of illness. Medicine, Health Care and Philosophy, 3, 125-137.

Trivedi, P., \& Wykes, T. (2002). From passive subjects to equal partners: Qualitative review of user involvement in research. British Journal of Psychiatry, 181, 468-472. 
van Manen, M. (1990). Researching lived experience: Human science for an action sensitive pedagogy. New York: State University of New York Press.

Veseth, M., Binder, P. E., Borg, M., \& Davidson, L. (2012). Toward caring for oneself in a life of intense ups and downs. A reflexive-collaborative exploration of recovery in bipolar disorder. Qualitative Health Research, 22, 119-133. Published online 2011 June 8.

Woods, S. W. (2000). The economic burden of bipolar disease. Journal of Clinical Psychiatry, 61, $38-41$.

\section{Authors}

Marius Veseth (Department of Clinical Psychology, University of Bergen, Norway and MoodNet Research Group, Haukeland University Hospital, Bergen, Norway), Per-Einar Binder (Department of Clinical Psychology, University of Bergen, Norway), Marit Borg (MoodNet Research Group, Haukeland University Hospital, Bergen, Norway and Department of Health Sciences, Buskerud University College, Drammen, Norway) and Larry Davidson (Program for Recovery and Community Health, Yale University, New Haven, USA). Corresponding author: Marius Veseth. Email: marius.veseth@gmail.com 